\title{
Magnetic Storm Effects on the Tropical Ultraviolet Airglow
}

\author{
J.-C. GÉRARD \\ Laboratory for Atmospheric and Space Physics, University of Colorado, Boulder, Colorado 80309 \\ D. N. ANDERSON
}

Space Environment Laboratory, National Oceanic and Atmospheric Administration, Boulder, Colorado 80302

S. Matsushita

High Altitude Observatory, National Center for Atmospheric Research, Boulder, Colorado 80303

\begin{abstract}
The intensity and latitudinal distribution of the O I 1304- and 1356- $\AA$ nighttime emissions associated with the equatorial anomaly have been observed by the ultraviolet spectrometer on board the Ogo 4 satellite. Conspicuous effects, apparently related to magnetic activity, have been noticed during the geomagnetic storm of October 29 to November 4, 1968. These effects include (1) large latitudinal variations of the $1304 / 1356-\dot{A}$ intensity ratio, (2) large interhemispheric asymmetries in the $1356-\dot{A}$ intensity, and (3) a pronounced longitude dependence in the airglow intensity during the recovery phase The results of model calculations allowing for changes in the vertical $\mathbf{E} \times \mathbf{B}$ drift velocity, the meridional and zonal wind velocity, and neutral composition are discussed. The variations of the 1304/1356-Á ratio can be accounted for by changes in the altitude of the $F$ layer due to neutral wind and $\mathrm{E} \times \mathrm{B}$ drift. Zonal wind speeds approaching $300 \mathrm{~m} / \mathrm{s}$ explain the interhemispheric asymmetries observed in the Pacific sector, and both drift velocity and composition changes can explain the longitudinal differences observed during the recovery phase. In addition, it is found that the ratio $1304 / 1356 \AA$ well. independent of which $\mathrm{E} \times \mathrm{B}$ drift or neutral wind model is used.
\end{abstract}

\section{INTRODUCTION}

The presence of ultraviolet arcs at about $12^{\circ}$ on each side of the magnetic dip equator was first observed in the nightglow by the Ogo 4 satellite [Hicks and Chubb, 1970; Barth and Schaffner, 1970] and later photographed from the moon [Carruthers and Page, 1976]. The emissions were identified by Barth and Schaffner [1970] as the O I $2 p^{4}{ }^{3} P-3 s^{3} S$ and $2 p^{4}{ }^{3} P-3 s{ }^{5} S$ transitions at 1304 and $1356 \dot{A}$, respectively. Other emissions, such as [O I] $\lambda 6300,5577 \AA$, O I $\lambda 7774 \AA$, and [N I] $\lambda 5200 \AA$, have been observed from the ground with enhanced intensity in the subtropical regions (cf. review by Kulkarni [1974]). Hanson [1969] suggested that the atomic oxygen emissions at 1304 , 36 , and $7774 \dot{A}$ are excited by radiative recombination of $\mathrm{O}^{+}$ions, whose intensity is enhanced in the equatorial anomaly through the process

$$
\begin{gathered}
\mathrm{O}^{+}+e \rightarrow \mathrm{O}^{*}+h \nu_{c} \\
\mathrm{O}^{*} \rightarrow \mathrm{O}\left({ }^{3} P\right)+\sum h \nu
\end{gathered}
$$

where $h v_{c}$ indicates continuum photons carrying the excess energy of the recombination and $\sum h v$ represents the sum of the discrete emission including cascades. Ion neutralization was also proposed by Knudsen [1970] as a possible mechanism, but Hanson [1970], D. N. Anderson [1972], and Tinsley et al. [1973] showed that this process makes only a minor contribution to the total intensity. Meier and Opal [1973] showed that the quadratic relationship between the $1356-\AA$ intensity and the peak electron density indicates that radiative recombination is the dominant excitation process. The 1304- and 1356-Á emission rates calculated by Hanson [1969] and D. N. Anderson [1972] tend to be smaller than the observed ones. However, when simultaneous measurements of the electron profile and $O$

Copyright $\odot 1977$ by the American Geophysical Union.
I 1356- $\dot{\mathrm{A}}$ [Meier and Opal, 1973] or $7774-\AA$ intensities are made [Tinsley et al., 1973], a satisfactory agreement is obtained by using reaction (1). Finally, as further support for reaction (1), D. E. Anderson et al. [1976] report equatorial observations of the $911-\dot{A}$ continuum associated with $\mathrm{O}^{+}$recombination in the ${ }^{3} P$ state of atomic oxygen. The intensity of the continuum is in good agreement with the calculations based on radiative recombination of $\mathrm{O}^{+}$ions.

A puzzling problem unaccounted for so far by the theory is the variability of the $1304 / 1356-\AA$ ratio observed by Barth and Schaffner [1970] and more dramatically present in the data analyzed in this paper. The ratio ranges from about 2 to more than 20; the high values are usually associated with low $1356-\AA$ intensity. Our interpretation of these variations is based on the optical thickness of the $1304-\dot{A}$ radiation, and measurements of the ratio are used to estimate the altitude of the $F$ region peak relative to the satellite.

The nighttime $F$ region has been studied by optical techniques by $R$. J. Thomas and T.M. Donahue [1972] and by Thuillier and Blamont [1973], who used Ogo measurements of the $5577-\AA$ and $6300-\dot{A}$ distribution, respectively. A method based on the relative intensities of allowed 1356- $\dot{A}$ and forbidden $6300-\dot{A}$ emissions has been developed by Chandra et al. [1975] and Tinsley and Bittencourt [1975] to determine the maximum electron density and the height of the $F_{2}$ peak. Bittencourt et al. [1976] applied a technique described by Bittencourt and Tinsley [1976] to deduce the wind direction and velocity at night. In the present study, Ogo 4 measurements of the UV equatorial airglow made during a period which included a major magnetic storm were analyzed and used as an indicator of wind direction and velocities and $\mathbf{E} \times \mathbf{B}$ drift magnitude and phase. Other features of the airglow intensity and distribution are explained by storm-induced changes of the vertical drift velocity and/or neutral composition. The applicability and the limitations of this method are discussed. 


\section{Orbital Geometry and Absolute Calibration}

The University of Colorado ultraviolet spectrometer on board Ogo 4, described by Barth and Mackey [1969], is a t-m Ebert-Fastie spectrometer which scanned the $1100-$ to $3400-\dot{A}$ range in $37 \mathrm{~s}$ with a nominal resolution of $20 \AA \mathrm{A}$. The motion of the satellite between two successive scans was of the order of $250 \mathrm{~km}$ or $2.3^{\circ}$ of latitude. The line of sight of the instrument was pointing toward the center of the earth. The spacecraft was in a polar orbit and precessed in local time by $1.5^{\circ} /$ day. The altitude varied between about 415 and $900 \mathrm{~km}$. During the period of observations described in this paper its perigee was in the equatorial regions and moved from $8^{\circ} \mathrm{N}$ to $24^{\circ} \mathrm{S}$ between October 26 and November 6, 1968. As a consequence, the altitude at the geographic equator varied between 415 and $440 \mathrm{~km}$. Over this 10-day period in the Asian sector the satellite altitude at the northern crest $\left(+15^{\circ}\right.$ geomagnetic latitude) varied between 413 and $470 \mathrm{~km}$, while at the southern crest $\left(-15^{\circ}\right.$ geomagnetic latitude) it varied between 413 and 430 $\mathrm{km}$. The respective altitude variations in the Pacific sector were between 414 and $458 \mathrm{~km}$ at the northern crest and between 415 and $422 \mathrm{~km}$ at the southern crest.

Spectra obtained during the storm period were used to study atmospheric response to the magnetic disturbance. High-latitude results have been described by Gérard and Barth [1976, 1977]. Each spectrum was corrected for background noise and calibrated, and the emission rate of each feature was obtained by integrating the intensity on the line profile. In particular, all the spectra available at geomagnetic latitudes less than $25^{\circ}$ were processed in this way.

Absolute emission rates of the $1304-\dot{A}$ equatorial airglow based on the preflight calibration of the spectrometer occasionally reached more than $1 \mathrm{kR}$. Since the theoretical calculations can hardly account for such high intensities, we will examine whether a correction should be applied to the preflight calibration. The basis of the discussion is to compare intensities of the $1304-\bar{A}$ emissions or other features observed by this instrument with the results of other measurements made under similar conditions, as was suggested initially by Barth and Schaffner [1970].

1. The 1304- $\AA$ tropical airglow was observed in April and May 1968 by the Cosmos 215 Russian satellite [Sheffer, 1971]. The reported intensities are about a factor of 3 lower than the University of Colorado (CU) Ogo 4 values for the same local time, a few weeks after the fall equinox of the same year.

2. A comparison between the 1304- $\AA$ dayglow emission rates observed by the $\mathrm{CU}$ and Naval Research Laboratory (NRL) instruments on Ogo 4 has been made by Meier and Prinz [1971]. They found that the intensities reported by G. Thomas [1970] from the CU instrument are greater by a factor of 2-3 than their measurements for the same period. Unfortunately, the NRL sensitivity deteriorated with time and had to be corrected; the correction was based on a comparison with another channel of the same experiment.

3. The intensity of Lyman alpha $1216 \AA$ probably provides the most reliable method to correct the instrument sensitivity. The solar flux at the center of the Lyman alpha line has been deduced from various instruments [G. Thomas and D. E. Anderson, 1976 ] for a given value of solar aciivity. The differences between these values reflect errors in the absolute calibration of the instruments. The CU Ogo 4 intensities obtained from the spectra processed for this study are about 1.4 times as large as the NRL Ogo 4 or Oso 4 values observed by Meier and Mange [1973] for the same solar zenith angle. On the other hand, more recent observations (CU experiments on Ogo 5 and Ogo 6) give Lyman alpha center fluxes 1.5-2 times lower than the NRL Ogo 4 values and about 2.3 times lower than the CU' ${ }^{\prime}$ - fluxes.

Since a downward revision of Ogo 4 absolute intensities seemed warranted, we decreased the intensities based on the preflight calibration by a factor of 2.3 , which represents the average correction to within $50 \%$.

\section{The Observations}

\section{The Storm}

The observations reported in this paper were made between October 26 and November 6, 1968. Low magnetic activity $(K p$ $\leq 3$ ) characterized the period before and including October 26 and 27 . The period October 31 to November 6 saw the onset and recovery of the most disturbed period of 1968 . The peak of the main phase occurred during the afternoon of November 1 and reached $K p=8+$. The storm actually consisted of a series of at least three storms with ssc's observed at 0909 UT on October 29, at 0859 UT on October 31, and 0916 UT on November 1 [World Data Center A, 1970]. The values of the $K p$ index and the Dst disturbance are plotted in Figure 1.

Some of the measurements of the 1304- and 1356- $\AA$ tropical airglow are plotted in Figure 2 as a function of latitude. The arrows indicate approximately the location of the magnetic dip equator at $F$ region altitudes. The data are divided into two sectors: the Asian sector (approximately $0^{\circ}-175^{\circ} \mathrm{E}$ ), where the dip equator is roughly parallel to the geographic equator, and the Pacific sector (approximately $175^{\circ} \mathrm{E}-60^{\circ} \mathrm{W}$ ), where the eastward declination is of the order of $10^{\circ}$. The mode of operation of the spacecraft prevented data from being obtained on each orbit. Over this period the local time of the equatorial crossing varied from 2145 to 2040.

Several features of the behavior of the ultraviolet tropical airglow during this period are readily observed: (1) The intensities of both emissions normally peak on each side of the dip equator as was previously observed by Hicks and Chubb [1970], Barth and Schaffner [1970], and D. E. Anderson et al. [1976]. (2) The crest intensities are quite variable, ranging from below threshold sensitivity $(\sim 40 \mathrm{R})$ to more than $500 \mathrm{R}$ in the 1304- $\AA$ line. (3) Interhemispheric asymmetries are often observed, especially in the $1356-\dot{A}$ line in the Pacific sector. (4) The $1304 / 1356-\AA$ ratio exhibits large variations. When intensities are integrated on the latitudinal extent of the arcs, this ratio roughly ranges between 2 and more than 20 .

We first examine the $1304 / 1356-\bar{A}$ ratio and provide an interpretation of these variations.

\section{The $1304 / 1356-\AA$ Ratio}

The volume emission rate $\eta$ of an emission excited by reaction ( 1 ) in the $F$ region is given by

$$
\eta_{t}=\alpha_{t}\left[\mathrm{O}^{+}\right][e] \simeq \alpha_{i}[e]^{2}
$$

where $\alpha_{\iota}$ is the radiative recombination coefficient (including cascades) in the level $i$ of the oxygen atom. Consequently, the $1304 / 1356-\AA$ production rate ratio is simply given by $\alpha_{1304} / \alpha_{1956}$. The slant emission rate observed from the satellite is given by the height integral of reaction (2) for an optically thin radiation. In the case of the $1304-\bar{A}$ radiation the optical thickness of the atmosphere must be taken into account. It affects the intensity of the emission in two ways.

1. As was discussed by Julienne et al. [1974], the optica] thickness of the $3 d^{3}-2 p^{4}$ and $n s^{3}-2 p^{4}$ transitions increases the 


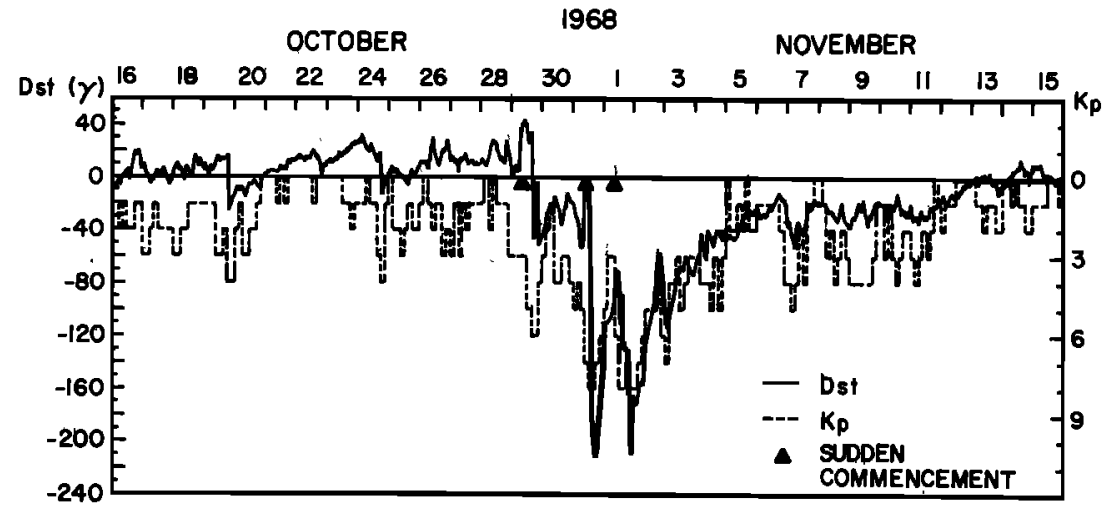

Fig. 1. Equatorial $D s t$ and $K p$ indices for the period October 16 through November 15, 1968. Sudden commencements are also indicated.
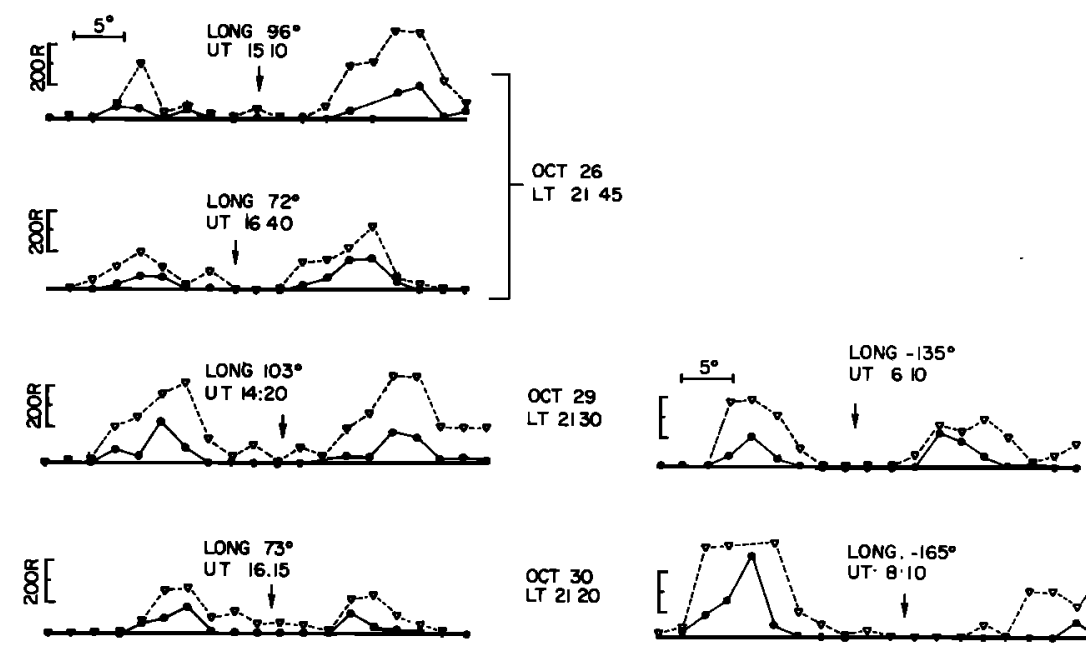

OCT 2120
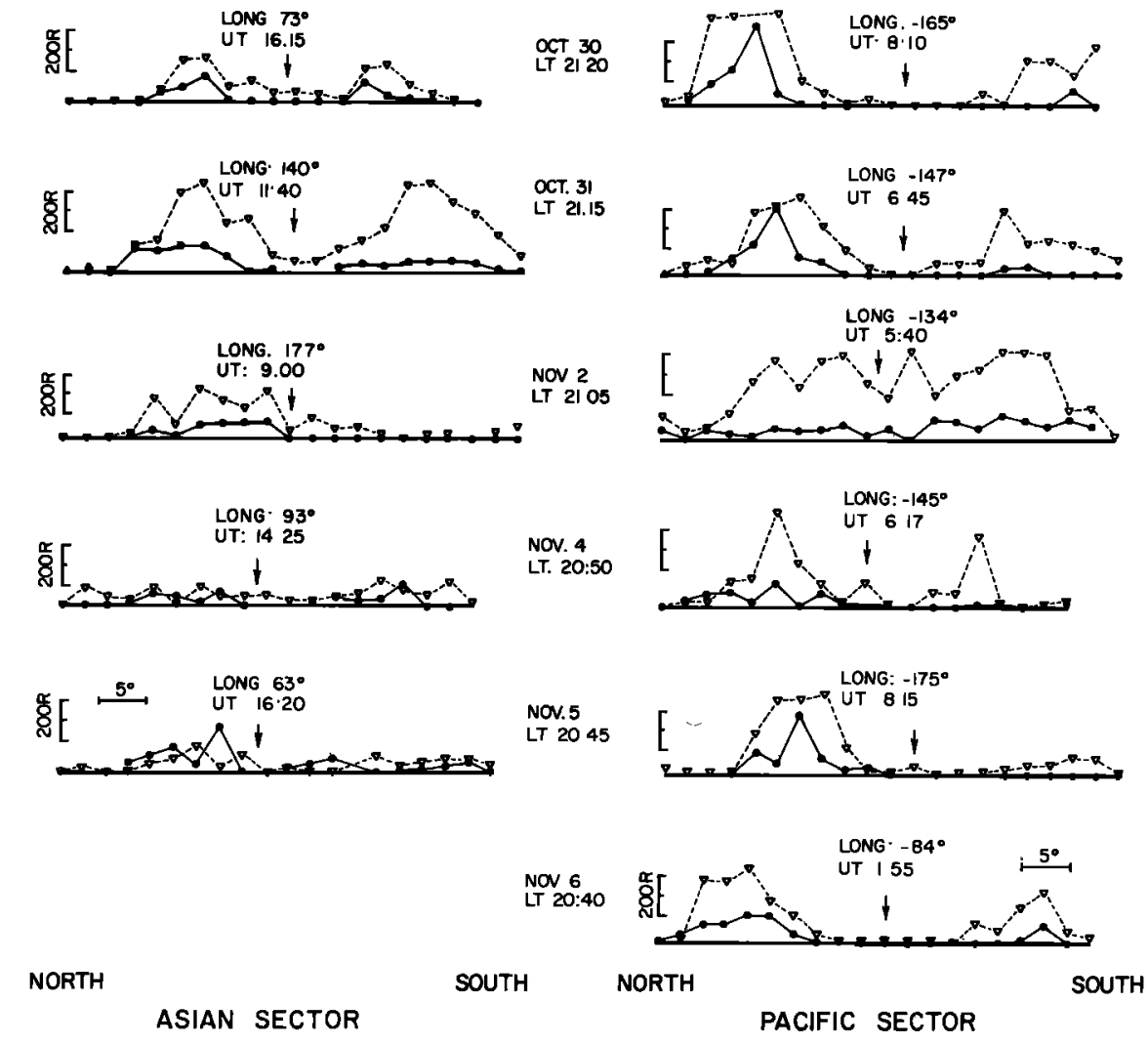

Fig. 2. Emission rates at $1304 \AA$ (dashed line) and $1356 \AA$ (solid line) observed by Ogo 4 as a function of dip latitude. Arrow indicates the dip equator, and $5^{\circ}$ bar represents $5^{\circ}$ in dip latitude or approximately $10^{\circ}$ in dip angle. 
value of $\alpha_{1304}$ from $4.9 \times 10^{-14} \mathrm{~cm}^{3} \mathrm{~s}^{-1}(\tau=0)$ to $2.8 \times 10^{-1 \mathrm{~s}}$ $\mathrm{cm}^{8} \mathrm{~s}^{-1}(\tau=\infty)$. In the following discussion, values of $\alpha_{136 \theta}=$ $4.9 \times 10^{-13} \mathrm{~cm}^{3} \mathrm{~s}^{-1}$ and $\alpha_{1304}=2.8 \times 10^{-13} \mathrm{~cm}^{3} \mathrm{~s}^{-1}$ will be used [Julienne et al., 1974].

2. Multiple scattering in the $1304-\bar{A}{ }^{3} P-{ }^{3} S$ transition itself is important. It has the effect of enhancing the apparent intensity of a nadir observation by a factor $C>1$ dependent on the altitude distribution of the production function. Strickland and Anderson [1977] have shown that the ratio $C$ of the $1304-\AA$ intensity emerging from the atmosphere to the column production rate is between 3 and 4 in the case of a source function such as the tropical airglow. The upper limit of 4 is obtained in the case of a photon source at high altitude with no pure absorber. Indeed, in this case, $F^{+}=\Pi I^{+}=\eta$ and $C=4 \Pi I^{+} / \eta$ $=4$, where $\eta$ is the column production rate and $F^{+}$and $I^{+}$are the emerging flux and intensity, respectively.

Consequently, for a satellite at infinity the intensities are given by

$$
\begin{aligned}
& I_{1304}=C \alpha_{1304} \int_{0}^{\infty}\left[\mathrm{O}^{+}\right]^{2} d z \\
& I_{1958}=\alpha_{1356} \int_{0}^{\infty}\left[\mathrm{O}^{+}\right]^{2} d z
\end{aligned}
$$

with an intensity ratio $R=C \alpha_{1304} / \alpha_{1350}$. For an observer far above the layer, $C \simeq 3.5$ and $R \simeq 2$. This result coincides with the lower limit of our measured ratios. We interpret the larger ratios to be due to the finite altitude of the spacecraft, particularly at the period when the satellite was near perigee at the equator. The average daily intensities given in Barth and Schaffner's [1970] Table 1 show the same trend: the largest 1304/1356-Á ratios tend to occur near the beginning of November 1967, when the Ogo 4 perigee was again close to the equator. With this orbital geometry an important fraction of the $F$ layer may have been above the instrument and would not have contributed to the $1356-\hat{A}$ intensity seen by the nadirlooking spectrometer. On the other hand, $1304-\AA$ photons initially created in an optically thick atmosphere produce an emission rate which is a slowly varying function of the altitude. Consequently, the $1304 / 1356-\dot{A}$ ratio will increase above 2 , depending on the relative altitude of the satellite and the $F$ peak. A detailed computation of the 1304-Á intensity distribution was made by D. E. Anderson (private communication, 1976 ) in the case of one of the $F$ layer profiles calculated hereafter. The results show that for a given electron profile the nadir $1304-\hat{A}$ emission rate varies by less than $50 \%$ from $50 \mathrm{~km}$ below the peak to infinity. This is the effect of the $\mathrm{O} \mathrm{I}^{3} \mathrm{P}-{ }^{3} \mathrm{~S}$ large optical thickness in the $F$ region. Consequently, we have considered $C$ to be constant at $\sim 3.5$ throughout the layer, although this may not be strictly correct.

\section{Storm Effects on the Tropical Airglow}

In Figure 2 the October 26 and 29 (135 $\mathrm{W}$ longitude), 1968, data are typical of quiet time tropical airglow during that time of year. They show some interhemispheric asymmetries, and intensities at the crests are of the order of $150 \mathrm{R}$ at $1356 \hat{A}$ and $350 \mathrm{R}$ at $1304 \AA$. The crests are at approximately $15^{\circ} \mathrm{dip}$ latitude. The measurements of October 29 and 30 show no significant asymmetries in the Asian sector but exhibit a substantial $1304-\AA$ intensity in the equatorial trough. On October 30 in the Pacific sector the $1356-\AA$ n northern arc was much brighter than the southern one. On October 31 the northern arc was brighter than the southern one in both sectors, and the crest intensities reached $440 \mathrm{R}$ in $1304 \AA$ A. High $1304 / 1356-\AA$ ratios were observed in the southern arcs. Again, the 1304- $\AA$ intensity in the equatorial trough region was of the order of 50 R. On November 2, only the northern arc was clearly defined at $177^{\circ} \mathrm{E}$, whereas at $134^{\circ} \mathrm{W}$ the pattern was dramatically different from the previous days: the trough disappeared in both emissions, and the tropical airglow consisted of a broad region showing a wavy structure and a high 1304/1356- $\dot{A}$ ratio. The measurements of November 4 and 5 in the Asian sector show the same type of structure with depressed intensities of the order of $50 \mathrm{R}$ in both lines. The Pacific sector had recovered its normal pattern on November 5 , and very large $1356-\AA \AA \AA$ asymmetries were observed. The November 6 distribution was nearly normal, but $1356-\AA$ asymmetries were still present.

To illustrate longitudinal effects on November 4 in more detail, Figure 3 shows the observations made on five passes in chronological order, corresponding to an apparent westward motion of the satellite. It can be seen that only the data between geographic longitude $142^{\circ}$ and $93^{\circ}$ show depressed intensities and the absence of regular structure. At longitude $19^{\circ}$ the equatorial anomaly has its usual pattern. This cannot be interpreted as a UT effect, since measurements made at $63^{\circ}$ on the following day still show a disturbed structure (Figure 2). Consequently, a longitudinal effect would seem to explain the observations. As will be discussed later, one can possibly attribute the depressed intensities to changes in the neutral composition which enrich the $F$ region in molecular constituents and thereby increase the loss rate of electrons and depress the airglow intensities. However, only the sector east of $19^{\circ}$ and west of $-145^{\circ}$ has been affected by composition changes. European ionograms show a depression of $f_{o} F_{2}$ on November 2 and 3 but a recovery to prestorm values on November 4 , in agreement with the tropical airglow measurements in this sector. At Kodaikanal ( $1^{\circ} \mathrm{N}$ dip latitude, $77^{\circ} \mathrm{E}$ longitude), however, $f_{0} F_{2}$ values were depressed throughout the day of No-
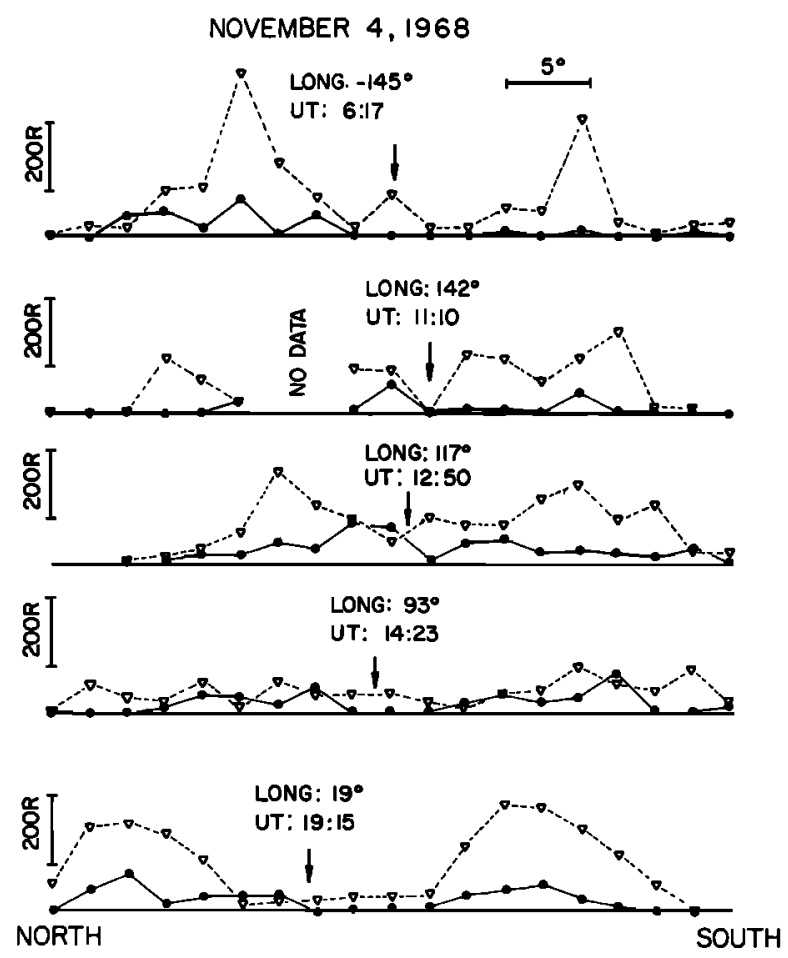

Fig. 3. Emission rates at $1304 \AA$ (dashed line) and at $1356 \AA$ (solid line) observed by Ogo 4 on November 4, 1968. Arrow indicates the dip equator. 
vember $4(9 \mathrm{MHz}$ compared with a monthly median value of $11 \mathrm{MHz}$ ), a result suggesting that the neutral atmosphere was altered through the recovery phase at this longitude. Measurements of the $N_{\max }$ and total electron content made in Hong Kong $\left(15^{\circ} \mathrm{N}\right.$ dip latitude, $114^{\circ} \mathrm{E}$ longitude) show that densities were $\sim 50 \%$ lower than quiet time values in November (G. $O$. Walker, private communication, 1976), but $N_{\max }$ at Manila ( $7^{\circ}$ dip latitude, $121^{\circ} \mathrm{E}$ longitude) was larger than normal. This behavior is consistent with the airglow observations showing at this time a crest-to-trough intensity ratio smaller than that in quiet conditions. The ionograms show that the same characteristics were observed in this sector on November 5.

\section{Model Calculations}

In order to calculate $1304-$ and $1356-\AA$ emission rates to compare with Ogo 4 observations, electron and ion density profiles must be known. This section describes briefly the density calculations and the relevant models entering into the calculations.

Production, loss, and transport of ionization determine the time rate of change of the $\mathrm{O}^{+}$ion (and electron) density as given by the plasma continuity equation

$$
\partial N_{t} / \partial t=P_{t}-L_{t}-\nabla \cdot\left(N_{i} V_{t}\right)
$$

where $P_{l}$ is the photo-ionization production rate, $L_{i}$ is the loss rate due to charge exchange with $\mathrm{N}_{2}$ and $\mathrm{O}_{2}$, and $V_{l}$ is the transport velocity and includes ambipolar diffusion, neutral wind, and $\mathbf{E} \times \mathbf{B}$ drift. In the low-latitude $F$ region, transport by vertical $\mathbf{E} \times \mathbf{B}$ drift is especially significant in determining the electron and ion density distributions [Sterling et al., 1969; D. N. Anderson, 1973b].

Solving (3) at low latitudes necessitates transforming the independent coordinates $r, \theta$, and $\phi$ to a coordinate system parallel and perpendicular to the magnetic field line [see $D . N$. Anderson, 1973a]. Equation (3) can be written

$\left(\partial N_{i} / \partial t\right)+\mathrm{V}_{i \perp} \cdot \nabla N_{l}=P_{l}-L_{l}-\nabla \cdot\left(N \mathrm{~V}_{l \|}\right)-N_{i} \nabla \cdot \mathrm{V}_{i \perp}$

where $\mathbf{V}_{i \perp}$ is given by $\mathrm{E} \times \mathrm{B} / \boldsymbol{B}^{2}$ and $\mathrm{V}_{l \mid}$ includes the effects of plasma diffusion and the neutral wind [Kendall and Pickering, 1967]. The left side of (4) is the time rate of change of the ion density in a reference frame moving with the $\mathbf{E} \times \mathbf{B}$ drift velocity. The right side involves terms which are second order in the coordinate parallel to B. Equation (4) can be solved numerically (see $D . N$. Anderson [1973a] for details) to give ion densities as a function of altitude, latitude, and local time. It is assumed that $\mathrm{O}^{+}$is the dominant ion in the low-latitude $\mathrm{F}$ region, so that $n(e)=n\left(\mathrm{O}^{+}\right)$and $n\left(\mathrm{O}_{2}^{+}\right), n\left(\mathrm{NO}^{+}\right)$, and $n\left(\mathrm{H}^{+}\right)$ give negligible contributions to the electron density. The coefficients of this linear second-order partial differential equation are obtained from models of the neutral composition, neutral temperature, ion and electron temperatures, and production, loss, and diffusion rates as well as neutral wind and $\mathrm{E}$ $\times$ B drift velocity. Briefly, these models are as follows.

1. Jacchia's [1970] atmospheric model was used to calculate $\mathrm{N}_{2}, \mathrm{O}_{2}$, and $\mathrm{O}$ densities and the neutral temperature $T_{N}$ as a function of altitude, latitude, and local time. An $F_{10.7} \mathrm{~cm}$ flux value of 180 was adopted for this period. Production, loss, and diffusion rates are similar to those used by $D$. N. Anderson $[1973 b]$. For the photo-ionization coefficient at the top of the atmosphere, $\boldsymbol{P}_{\infty}$, two values were selected: $3.5 \times 10^{-7} \mathrm{~s}^{-1}$ to represent the quiet period (October 26-28 and November 5 and 6) and $5.5 \times 10^{-7} \mathrm{~s}^{-1}$ to represent the disturbed period (October 29 to November 4). At all altitudes and local times we assumed that $T_{i}=T_{e}=T_{N}$.

2. Very few measurements of the meridional and zonal components of the neutral wind have been made at low latitudes (see Bedinger [1970] and references therein). Concerning the zonal component, Woodman [1972] suggested that the eastward $\mathbf{E} \times \mathbf{B}$ plasma drift observed at the magnetic equator at night is due to an eastward $F$ region wind [Rishbeth, 1971]. D. N. Anderson and R. G. Roble [1974] have shown that when realistic electron density distributions are adopted, solution of the neutral momentum equation for the zonal wind produces an eastward component with a velocity of about $350 \mathrm{~m} / \mathrm{s}$ at 2100 LT near the magnetic equator. The zonal wind model that we adopted is patterned after these results and is given by one of the following expressions depending on dip latitude and local time. For $0600 \leq \mathrm{LT} \leq 1800$,

$$
u_{\mathrm{E}-\mathrm{w}}=100+200[\sin (H A-90)]
$$

For $1800<\mathrm{LT} \leq 2400$ and $\phi \leq 12^{\circ}$,

$$
u_{\mathrm{E}-\mathrm{w}}=100+200[\cos 7.5 \phi \cos 30(\mathrm{LT}-2100)]
$$

For $1800<\mathrm{LT} \leq 2400$ and $\phi>12^{\circ}$,

$$
u_{\mathrm{E}-\mathrm{w}}=100
$$

where $H A$ is the hour angle measured in degrees from noon and $\phi$ is dip latitude. Positive values correspond to an eastward wind in meters per second. At the dip equator the eastward wind reaches a maximum value of $300 \mathrm{~m} / \mathrm{s}$ at $2100 \mathrm{LT}$, falling off to $100 \mathrm{~m} / \mathrm{s}$ at latitudes greater than $\pm 12^{\circ}$. Before $1800 \mathrm{LT}$ the zonal wind is independent of latitude.

The meridional component of the neutral wind, which was incorporated in the calculations to help explain the observations on November 2 at $134^{\circ} \mathrm{W}$ geographic longitude (Figure 2 ), was patterned somewhat after the wind model of Roble et al. [1974], which in turn was based on incoherent scatter radar measurements obtained at Millstone Hill in March 1970. We used a model in which the meridional wind speed was specified at $\pm 45^{\circ}$ geomagnetic latitude $(\phi)$ and varied as $\sin 2 \phi$. The expression

$$
u_{\mathrm{N}-\mathrm{s}}=\{75[\sin (H A-90)]+50\} \sin 2 \phi
$$

gives the meridional component with positive values representing an equatorward-blowing wind. For both the zonal and the meridional models the wind speed was assumed constant with altitude.

In general, at the dip equator the transequatorial wind in the magnetic meridian plane may be written as

$$
u_{\|}=u_{\mathrm{E}-\mathrm{w}} \sin D+u_{\mathrm{N}-\mathrm{s}} \cos D
$$

where $u_{\|}$is the wind parallel to the magnetic field line, $u_{\mathrm{E}-\mathrm{w}}$ is the geographic zonal wind, $u_{\mathrm{N}-\mathrm{s}}$ is the geographic meridional wind, and $D$ is the magnetic declination. In the Asian sector, north-south asymmetries in the electron density can only be produced by an interhemispheric geographic meridional wind, since $D \simeq 0^{\circ}$, while in the Pacific sector $\left(D \simeq 10^{\circ} \mathrm{E}\right)$, geographic zonal and meridional winds can produce asymmetries.

It is not the intent of this paper to try to account quantitatively for observed north-south asymmetries in airglow intensity and in the $1304 / 1356-\AA$ ratio with various combinations of zonal and meridional winds and $\mathbf{E} \times \mathbf{B}$ drift models, but to account, qualitatively, for longitude related and storm time related differences which have been observed. Although 
north-south asymmetries do appear in the Asian sector (see Figure 2, October 26 and October 31), the lack of strong asymmetries leads us to conclude that a strong interhemispheric meridional wind is not present. We then assume that this is also the case for the Pacific sector and that the strong asymmetries observed in this sector (October 30, October 31, November 4, November 5) are due essentially to a zonal wind. Although the effects of gravity waves and traveling ionospheric disturbances (TID's) are known to be important during magnetic storms [Harper, 1972; Porter et al., 1974], we make no attempt to estimate or to model the importance of such effects for this particular disturbance.

3. The vertical $\mathbf{E} \times \mathbf{B}$ drift observed by Woodman [1970] is essential in producing and maintaining the electron density distribution observed near the magnetic equator. The drift models which produce electron density distributions and consequently airglow distributions most nearly matching the Ogo 4 observations were selected from a variety of models. Curves of three vertical drift models as a function of local time at the magnetic equator are shown in Figure 4. Note that the daytime drifts are identical in all three models and that major differences occur after $1800 \mathrm{LT}$. Such time variations in the vertical drift velocity have been observed [Woodman, 1970] and are not uncommon. In all cases we assumed that the drift velocity was independent of altitude (based on Woodman's observations of vertical drift up to $600 \mathrm{~km}$ ). Also, the horizontal east-west drift velocity (relative to the earth) was neglected [Woodman, 1972; Sterling et al., 1969].

\section{Discussion OF Results}

Numerical integration of (4) gives electron densities as a function of altitude, latitude, and local time. Electron densities calculated in this manner were interpolated to give values at every $4^{\circ}$ dip angle interval between $\pm 40^{\circ}$ dip $\left(\sim \pm 20^{\circ}\right.$ dip latitude), every $25 \mathrm{~km}$ in altitude between 200 and $1000 \mathrm{~km}$, and every half hour in local time. To obtain the 1304- and $1356-\AA$ volume production rates, the respective products $N_{e}^{2} \alpha_{1904}$ and $N_{e}^{2} \alpha_{1936}$ were formed. The contribution to 1304and $1356-\AA$ radiation by ion-ion neutralizaton probably accounts for less than $10 \%$ [D. N. Anderson, 1972] and so is neglected in this study. At every $4^{\circ}$ dip angle the volume production rates were integrated over altitude to give column production rates. For $1304-\hat{A}$ radiation the limits of integration were from 200 to $1000 \mathrm{~km}$, and since this radiation is optically thick, the column production rate was multiplied by $C \simeq 3.5$ to obtain the emission rate (see section $3,1304 / 1356-\AA$

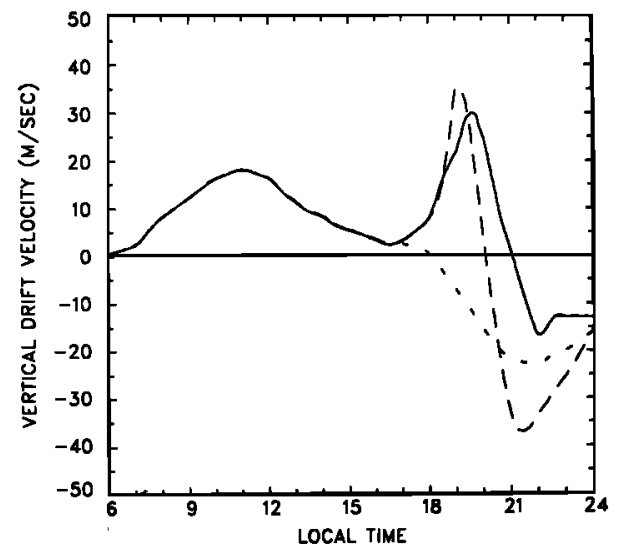

Fig. 4. Three models of the vertical $\mathbf{E} \times \mathbf{B}$ drift velocity (in meters per second) at the magnetic equator as a function of local time.

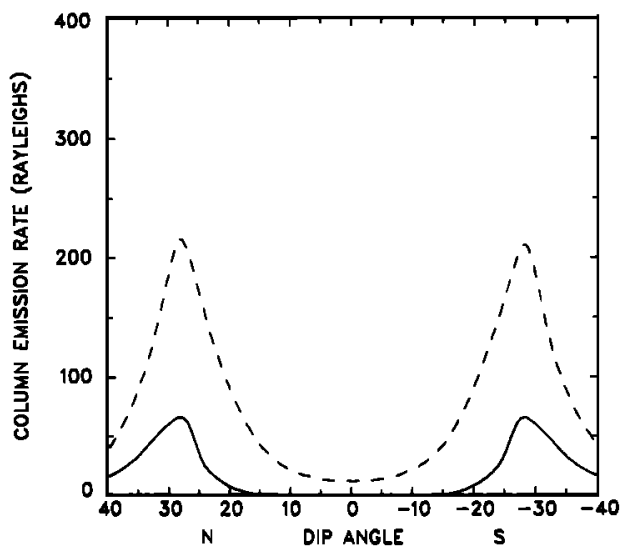

Fig. 5a. Calculated 1304- $\hat{A}$ (dashed line) and 1356- $\hat{A}$ (solid line) emission rates at $2130 \mathrm{LT}$. Input parameters are $P_{\mathrm{s}}=3.5 \times 10^{-7} \mathrm{~s}^{-1}$, $E \times B$ drift (solid line in Figure 4), and no neutral wind.

ratio). The contribution to the $1304-\AA$ column emission rate above $1000 \mathrm{~km}$ was found to be less than $1 \%$ for all cases considered. Since $1356-\AA$ radiation is optically thin, the limits of integration were from 200 to $425 \mathrm{~km}$, which was the nominal altitude of Ogo 4 in the equatorial region during this period of time. In this way, values of $1304-$ and $1356-\AA$ column emission rates were calculated every half hour in local time between 1800 and 2400 LT.

The calculated emission rates were compared to the Ogo 4 observations for the quiet period, October 26-29 and November 6 , and the storm period, October 29 to November 4 . To simulate the quiet time conditions, the ionization coefficient $P_{\infty}$ was assumed to be $3.5 \times 10^{-7} \mathrm{~s}^{-1}$, and the quiet time $\mathrm{E} \times \mathrm{B}$ drift model is depicted by the solid curve in Figure 4 . Use of the long-dashed and short-dashed curves will be discussed later. Both the zonal and the meridional neutral wind components were assumed to be zero during this period. As a consequence of upward $\mathbf{E} \times \mathbf{B}$ drift during the daytime, plasma is transported away from the magnetic equator to higher latitudes to form crests in ionization at roughly $\pm 15^{\circ}$ dip latitude [Baxter and Kendall, 1968; D. N. Anderson. 1973b]. This latitudinal distribution in electron density is referred to as the Appleton anomaly or the equatorial anomaly. After sunset, in the absence of photo-ionizing radiation, the behavior of this distribution is critically dependent on the time history of vertical $\mathrm{E} \times \mathrm{B}$ drift. Curves of the calculated 1304- $\dot{A}$ (dashed line) and $1356-\AA$ (solid line) column emission rates in rayleighs as a function of dip angle at $2130 \mathrm{LT}$ are plotted in Figure $5 a$.

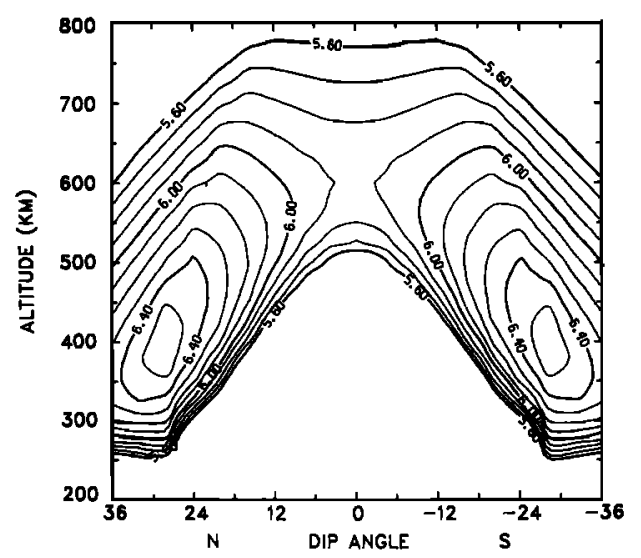

Fig. $5 b$. Contour plot of $\log N_{e}$ (electrons per cubic centimeter) at 2130 LT. Input parameters are the same as those in Figure $5 a$. 
In Figure $5 b$, contours of $\log N_{e}$ are plotted as a function of altitude and dip angle from which the emission rates are calculated. Roughly, the dip angle is approximately twice the dipole latitude. Positive dip angles lie north of the dip equator. The peaks in the $1304-$ and $1356-\AA$ emission rates at $\pm 28^{\circ}$ dip angle result from the increased ionization density at the crests. Notice in Figure $5 b$ that the maximum height of the $F$ layer $\left(H_{\max }\left(F_{2}\right)\right)$ at this latitude occurs at $400 \mathrm{~km}$ while at the magnetic equator its value is almost $600 \mathrm{~km}$. This disparity explains the change in the $1304 / 1356-\AA$ ratio with latitude. From $\pm 40^{\circ}$ dip angle to the equator the ratio changes from a value of about 2 to a value greater than 100. At the airglow peaks the ratio is 3 . As has been discussed previously, the ratio increases toward the equator because the observed 1356- $\AA$ emission diminishes below $425 \mathrm{~km}$ as the height of the $F$ layer increases.

The agreement between Figure $5 a$ and the observations in the Asian sector on October 26 and 29 is qualitative at best. The calculated $1304 / 1356-\dot{A}$ ratio at the crests is 3 , while the observed ratio in the Asian sector is about 2, a result indicating that the $F$ layer was somewhat lower than $400 \mathrm{~km}$. The observed crests occurred between $\pm 20^{\circ}$ and $\pm 30^{\circ}$ dip angle, in good agreement with the calculated results. Because no interhemispheric meridional neutral wind is included in the calculations, the southern hemisphere airglow enhancements on October 26 are not reproduced. However, from the lack of any observed strong asymmetry between the northern and southern crests in the Asian sector we conclude that strong interhemispheric meridional neutral winds were absent during this period. This does not preclude the existence of strong winds symmetric about the magnetic equator, however, since this type of wind would not produce any north-south asymmetries. For a given $\mathbf{E} \times \mathbf{B}$ drift model a meridional wind blowing equatorward would lift the layer in both hemispheres and increase the $1304 / 1356-\AA$ ratio, while a poleward wind would lower the $F$ layer and decrease the ratio.

The storm time period was simulated by increasing the value of $P_{\infty}$ from $3.5 \times 10^{-7} \mathrm{~s}^{-1}$ to $5.5 \times 10^{-7} \mathrm{~s}^{-1}$, the neutral composition, density, and temperature being unaltered. The $60 \%$ increase in the ionization coefficient was based on a $60 \%$ increase in the average $F_{10.7} \mathrm{~cm}$ flux for the period October 20 to November 20, 1968. The effect of changes in neutral composition and density on the airglow intensities is discussed later. In an attempt to reproduce the Asian sector observations of October 29 and 31 , we chose a slightly different $\mathbf{E} \times \mathbf{B} \mathrm{drift}$ model (long-dashed line in Figure 4) but still assumed that the meridional neutral wind was zero. The resulting 1304- $\AA$ and

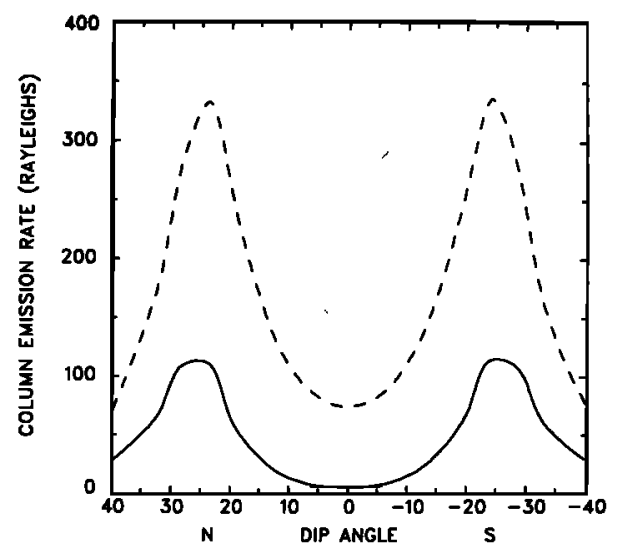

Fig. 6. Same as Figure 5a. Input parameters are $P_{\infty}=5.5 \times 10^{-7} \mathrm{~s}^{-1}$, $\mathbf{E} \times \mathbf{B}$ drift (long-dashed line in Figure 4), and no neutral wind.
1356- $\AA$ airglow intensities at $2130 \mathrm{LT}$ are shown in Figure 6. The increase in $1304-\dot{A}$ and $1356-\dot{A}$ intensity at the crests results primarily from the increased daytime production rate and not from the change in the $\mathrm{E} \times \mathrm{B}$ drift velocity. A $60 \%$ increase in the production rate gives a $38 \%$ increase in $N_{\max }$ at the crests, which translates into a $54 \%$ increase in the $1304-\AA$ column emission rate at $\pm 25^{\circ}$ dip angle. The increase in the $1304-\dot{A}$ intensity at the magnetic equator, however, is primarily due to the fact that downward $\mathbf{E} \times \mathbf{B}$ drift commences an hour earlier at $2000 \mathrm{LT}$ and is stronger, so that relatively more ionization is transported toward the equator. The calculated value of $75 \mathrm{R}$ of $1304-\dot{A}$ emission is in good agreement with the observed emission rate on October 31 .

In the Pacific sector, observations on October 30 , October 31 , and November 5 were characterized by large asymmetries in the 1304- and 1356- $\AA$ intensity and in the $1304 / 1356-\AA$ ratio. The airglow intensities were strongest in the northern hemisphere, while the $1304 / 1356-\AA$ ratio was largest in the southern hemisphere. This would be consistent with either a zonal wind blowing eastward or a transequatorial meridional wind blowing from south to north, or both. Such asymmetries cannot be attributed to north-south differences in satellite altitude, since this difference amounted to only $6 \mathrm{~km}$ between $+15^{\circ}$ and $-15^{\circ}$ geomagnetic latitude on October 30 and 31 . To simulate these observations, we incorporated the $\mathrm{E} \times \mathrm{B}$ drift model just described and added the zonal wind model described previously. The resulting 1304- and 1356- $\AA$ airglow intensities at $2100 \mathrm{LT}$ are displayed in Figure 7 . The strong eastward wind raises the $F$ layer in the southern hemisphere $\left(-25^{\circ} \mathrm{dip}\right)$ from 370 to $420 \mathrm{~km}$ and decreases $N_{\max }$ from $4.6 \times$ $10^{8} \mathrm{~cm}^{-3}$ to $3.3 \times 10^{8} \mathrm{~cm}^{-3}$. The $1304 / 1356-\dot{A}$ ratio increases to 5. On the basis of theoretical considerations $[D . N$. Anderson and $R$. G. Roble, 1974] and the observations of strong eastward plasma motion in the $F$ region [Woodman, 1972], a zonal wind rather than a transequatorial meridional wind appears to be the best candidate for producing the asymmetries observed in the Pacific sector. Previous observations by an Ogo 4 instrument (October 20 to November 11, 1967) of the northsouth asymmetry in the $1356-\dot{A}$ intensity in this sector have been attributed to a zonal wind component reaching a maximum eastward velocity of $260 \mathrm{~m} / \mathrm{s}$ near 2200 LT [Bittencourt et al., 1976]. We believe that the north-south asymmetries observed on October 30 , October 31 , and November 5 are longitude related rather than storm related, since the observa-

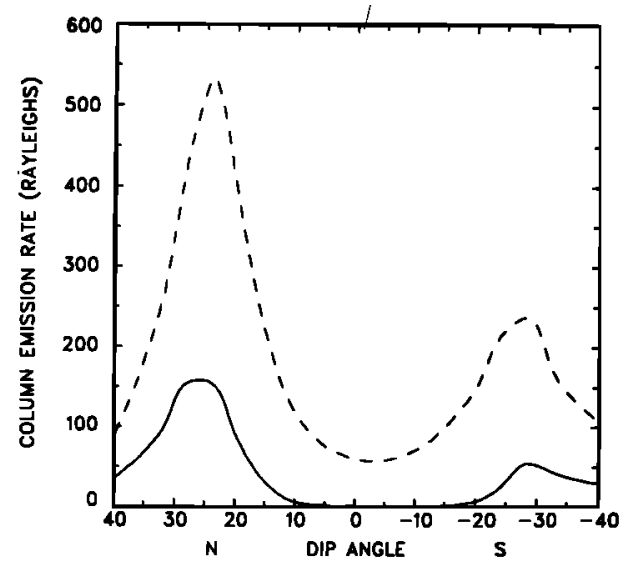

Fig. 7. Calculated 1304- $\dot{A}$ (dashed line) and 1356- $\dot{A}$ (solid line) emission rate at $2100 \mathrm{LT}$. Input parameters are $P_{\infty}=5.5 \times 10^{-7} \mathrm{~s}^{-1}, \mathrm{E}$ $\times$ B drift (long-dashed line in Figure 4 ), and zonal neutral wind. 
tions by Bittencourt et al. [1976] were made under quiet conditions.

In the Pacific sector the November 2 observation of the 1304-Á latitudinal intensity distribution was strikingly different from other days in this period. First, a significant amount of $1304-\hat{A}$ radiation was observed over the magnetic equator with an absence of any well-defined trough, and second, both the 1304- and the 1356- $\AA$ emissions possessed a wavelike structure. The 1304/1356- $\dot{A}$ ratio varied between 4 and 6 . We simulated the observations by adopting an $\mathbf{E} \times \mathbf{B}$ drift model (given by the short-dashed line in Figure 4) and included a meridional wind which is symmetric about the dip equator. The resulting 1304- and $1356-\bar{A}$ emission rates at 2100 LT are shown in Figure $8 a$ and the electron density contours in Figure $8 b$.

The effect of strong downward $\mathrm{E} \times \mathrm{B}$ drift after $1800 \mathrm{LT}$ is to transport plasma back toward the magnetic equator, thereby increasing the electron density there while also lowering the $F$ layer so that appreciable $1356-\dot{\AA}$ radiation is observed. The equatorward-blowing neutral wind also enhances the 1304- and 1356-A emission rates. The fact that the observed latitudinal extent of enhanced $1304-\AA$ emission is greater than the calculated extent of $\pm 20^{\circ}$ dip angle probably implies that the daytime upward drift was greater than the adopted value, the ionization crests thus being formed at higher latitudes prior to strong downward drift. Because no appreciable interhemispheric asymmetry in the 1304- and $1356-\AA$ intensities was observed, the implication is that the zonal wind velocity was reduced or absent.

Referring to Figure 3, the depressed intensities of 1304- and $1356-\AA$ emissions on November 4 at $93^{\circ} \mathrm{E}$ could be attributed to an increase in the neutral $\mathrm{N}_{2} / \mathrm{O}$ ratio [Prölss and von Zahn, 1974]. We investigated the effects of a composition change on electron densities and airglow intensities by increasing the $\mathbf{N}_{2}$ density at $120 \mathrm{~km}$ in Jacchia's [1970] neutral atmospheric model from $1.8 \times 10^{11} \mathrm{~cm}^{-3}$ to $5.58 \times 10^{11} \mathrm{~cm}^{-3}$. Both the $\mathrm{E} \times$ $B$ drift model and the meridional neutral wind model just described wère used. The resulting airglow intensities at 2100 LT are pictured in Figure 9. The electron density at $400 \mathrm{~km}$ is reduced by a factor of 1.65 , while the $1304-$ and $1356-\AA$ emission rates are a factor of 2.5 lower. The $F$ layer height is raised slightly $(\sim 20 \mathrm{~km})$ as a result of increasing the $\mathrm{N}_{2}$ density. Trinks et al. [1975] have measured the $\mathrm{N}_{2} / \mathrm{O}$ ratio at $300 \mathrm{~km}$ during and after a large geomagnetic storm and found that the ratio increased by as much as a factor of 5 at $20^{\circ}$ with enhance-

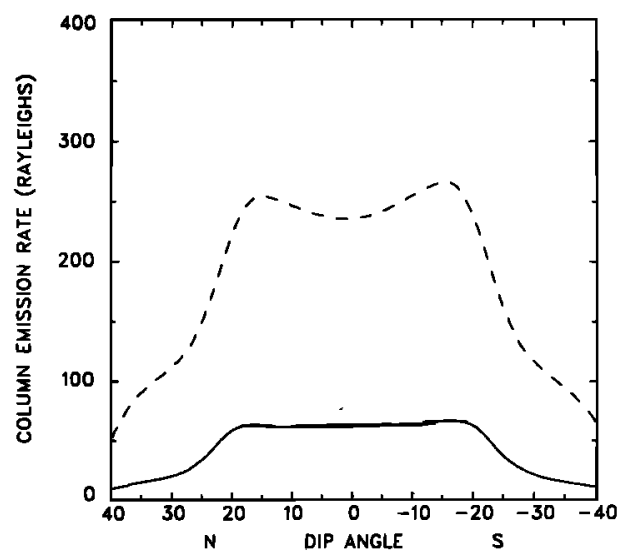

Fig. $8 a$. Same as Figure 7. Input parameters are $P_{\mathrm{m}}=5.5 \times 10^{-7}$ $\mathrm{s}^{-1}, \mathrm{E} \times \mathrm{B}$ drift (short-dashed line in Figure 4), and meridional neutral wind.

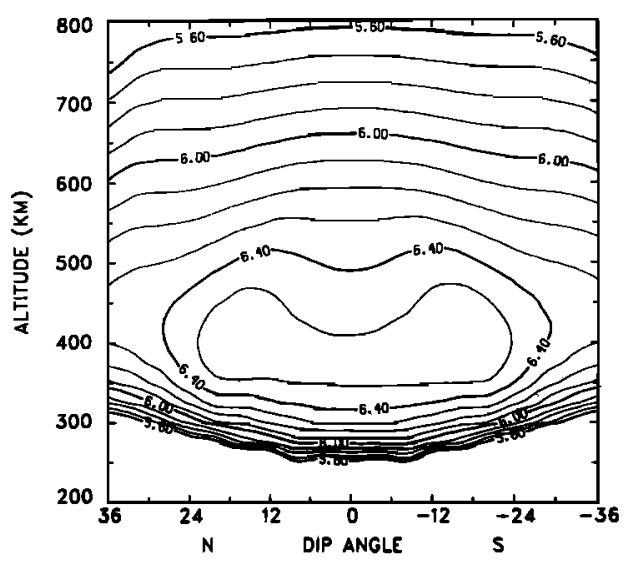

Fig. 8b. Contour plot of $\log N_{e}$ (electrons per cubic centimeter) at 2100 LT. Input parameters are the same as those in Figure $8 a$.

ments confined to relatively narrow longitude sectors. The enhancements can be sustained for many days after the storm, a fact suggesting that the atmosphere is disturbed down to altitudes below $150 \mathrm{~km}$, where the recovery time constant may be a half day or longer.

Although a neutral composition change is an attractive explanation for the depressed airglow intensities, the fact that the observed $1304 / 1356-\AA$ ratio is about 2 suggests that the $F$ layer was actually much lower than the calculated value of $420 \mathrm{~km}$, implying that downward drift began earlier than we have assumed. The effect would be to lower the $F$ layer into a higher loss rate region and to depress the electron density and the airglow intensities even more.

To determine if there is a theoretical relationship between the $1304 / 1356-\dot{A}$ ratio observed by a nadir-viewing instrument and altitude, we used the electron density contours pictured in Figure $S b$ to calculate the ratio

$$
\left(3.5 \int_{0}^{1000 \mathrm{~km}} \alpha_{1304} N_{e}^{2} d z\right) /\left(\int_{0}^{h} \alpha_{1980} N_{e}^{2} d z\right)
$$

The resulting contours for the ratio $R$, equal to 3,6 , and 9 , are shown in Figure 10a. When the $R=6$ ratio is isolated and superimposed on the electron density contour plot as a dashed line, Figure $10 b$ is obtained. This particular ratio appears to map $H_{\max }\left(F_{2}\right)$ very well. At the equator, $R=3$ occurs $70 \mathrm{~km}$ above $H_{\max }\left(F_{2}\right)$, while $R=9$ lies $25 \mathrm{~km}$ below. At the crests ( $\pm 28^{\circ} \mathrm{dip}$ ) the respective distances for $R=3$ and $R=9$ are 65 $\mathrm{km}$ and $25 \mathrm{~km}$. To determine if the $R=6$ line still maps

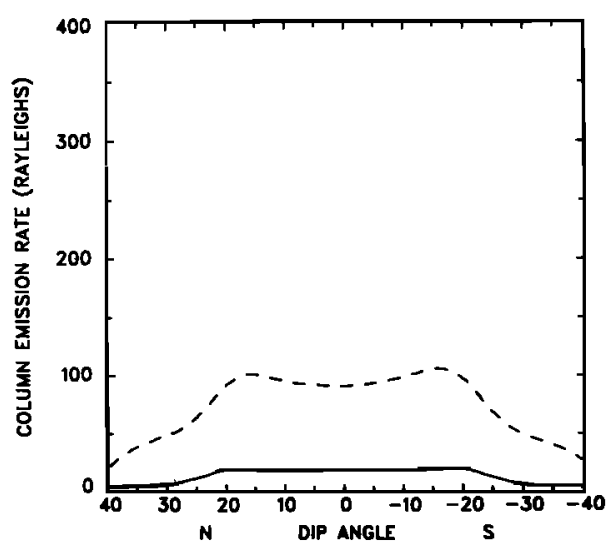

Fig. 9. Same as Figure $8 a$ except $\mathrm{N}_{2}$ density at $120 \mathrm{~km}$ is increased by a factor of 3 . 


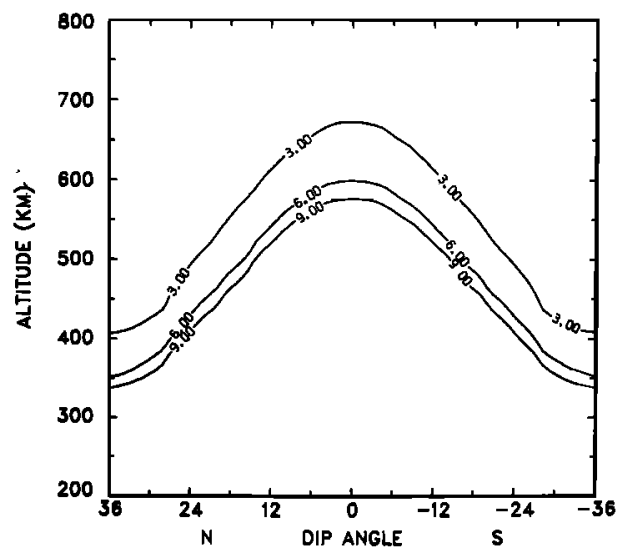

Fig. 10a. Contours of the $1304 / 1356-\hat{A}$ intensity ratio calculated from the electron density profiles shown in Figure $5 b$. See text for details.

$H_{\max }\left(F_{2}\right)$ for a different $\mathrm{E} \times \mathrm{B}$ drift model, we used the electron density results pictured in Figure $8 b$ to calculate the 1304/1356- $\AA$ ratio and then superimposed the $R=6$ value to give Figure 10c. The agreement is still good, although the $R=$ 3 and $R=9$ values do not give exactly the same distances above and below $H_{\max }\left(F_{2}\right)$ as those given in Figure 10a. For this electron density distribution, $R=3$ occurs $80 \mathrm{~km}$ above $H_{\max }\left(F_{2}\right)$ while $R=9$ occurs $25 \mathrm{~km}$ below, with both these distances applying over the entire $\pm 36^{\circ}$ dip angle range.

It should be emphasized that these ratios could only be observed by a nadir-looking spectrometer on board a satellite. In actuality, such a satellite moving through the ionosphere at a constant altitude would observe a dramatically changing value of $R$ as the height of the $F$ layer, relative to the satellite, varied. The satellite would encounter the value $R \simeq 6$ where the $F$ layer peak was at the satellite altitude. It must be remembered, however, that this value of 6 depends on certain assumptions that we have made which may or may not be strictly true. It was assumed, for example, that the influence of ion-ion recombination on the airglow intensity was negligible, where, in fact, at the altitudes appropriate to this study it may account for $10 \%$ of the intensity. As the altitude of the $F$ layer decreases, the ion-ion contribution to airglow increases.

Another uncertainty lies in the value of $C$ which we have chosen (see section 3 , the $1304 / 1356-\dot{A}$ ratio). $C$ is the ratio of the emergent nadir $1304-\AA$ intensity to its column production rate, and, as Strickland and Anderson [1977] have shown, it is

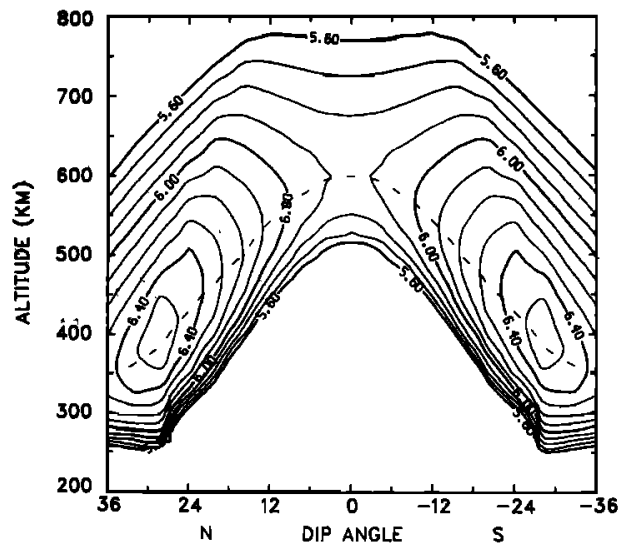

Fig. 10b. Contour plot of $\log N_{e}$ shown in Figure $5 b$ with the 1304/1356- $\dot{A}$ intensity ratio $R=6$ superimposed as a dashed line.

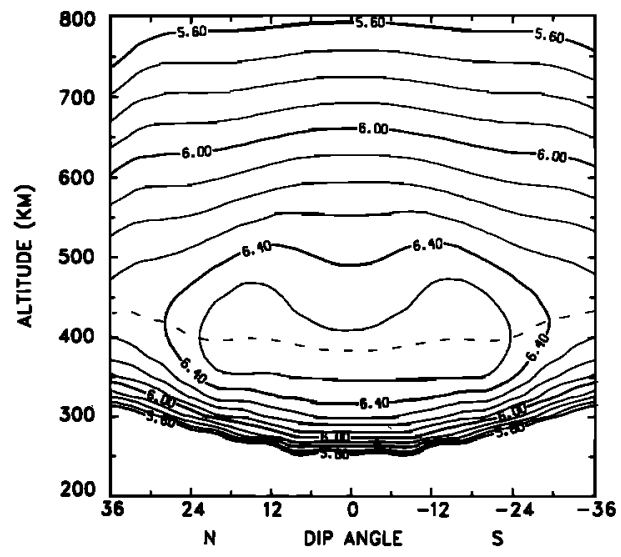

Fig. $10 c$. Contour plot of $\log N_{e}$ shown in Figure $8 b$ with the $1304 / 1356-\hat{A}$ intensity ratio $R=6$ superimposed as a dashed line.

dependent on the altitude profile of the volume production rate and may not be constant with altitude as we have assumed. Finally, the value of $\alpha_{1304}$ does vary with optical depth [Julienne et al., 1974], which may give rise to a height variation in this quantity. We have assumed it to be height independent. - Considering these uncertainties it would be desirable to measure the ratio $R$ and the value of $H_{\max }\left(F_{2}\right)$ simultaneously in order to estimate the appropriate height-integrated value for $C$. This possibility is being further studied with data obtained by the Ogo 4 satellite. Until such a 'calibration' is performed, estimating $H_{\max }\left(F_{2}\right)$ from the observed $1304 / 1356-\AA$ ratio cannot be accomplished.

\section{Summary and Conclusions}

Observations of the tropical ultraviolet airglow of oxygen at $1304 \dot{A}$ and $1356 \dot{A}$ near the magnetic equator have been obtained by an ultraviolet spectrometer aboard the Ogo 4 satellite during the period October 26 to November 6, 1968. After comparing the measured $1216-\AA$ and $1304-\AA$ intensities with emission rates obtained by other instruments at this time the preflight calibration intensities for the $1304-\bar{A}$ and $1356-\AA$ lines were reduced by a factor of 2.3 prior to analyzing the data.

In both Asian and Pacific sectors, on the average, the $1304 / 1356-\AA$ ratio increases from a value of 2 to a value greater than 20 in going from $\pm 15^{\circ}$ dip latitude toward the equator. This is explained by the fact that the $1356-\AA$ line is optically thin, so that the emission rate observed by the downward-looking spectrometer at $425 \mathrm{~km}$ results only from radiation originating below the satellite. As latitude decreases, the height of the $F$ layer increases, so that less and less $1356-\AA$ emission is seen by the spectrometer relative to the optically thick $1304-\AA$ emission.

In the Asian sector, where the magnetic field declination is essentially zero, peaks in the $1304-$ and $1356-\AA$ intensity are roughly symmetric about the dip equator, a finding implying the absence of a transequatorial meridional neutral wind. In the Pacific sector, however, the 1304- and 1356- $\AA$ emission rates are enhanced in the northern hemisphere relative to the southern hemisphere, while the $1304 / 1356-\AA$ ratio is greater in the south than in the north. The observations are consistent with an eastward neutral wind which transports ionization from the southern to the northern hemisphere while it raises the $F$ layer in the south and lowers it in the north. Theoretically modeling the low-latitude $F$ region ionosphere indicates 
that an eastward wind approaching $300 \mathrm{~m} / \mathrm{s}$ at $2100 \mathrm{LT}$ can qualitatively produce the observed asymmetries (see neutral wind models, section 4). Such high wind velocities are also implied by the Bittencourt et al. [1976] observations of the 6300/1356-A ratio in the tropical airglow. Neutral wind velocities calculated from neutral pressure gradient forces [Challinor, 1969; D. N. Anderson and R. G. Roble, 1974] also suggest that the zonal wind speed is about $300 \mathrm{~m} / \mathrm{s}$ at low latitudes near $2100 \mathrm{LT}$. This value probably represents an average wind speed. The actual variation of the wind with latitude is expected to be quite complex.

On November 2 at $134^{\circ} \mathrm{W}$ geographic longitude the normal trough in the 1304- and $1356-\dot{A}$ emission at the dip equator is absent, and the intensity distribution is essentially flat between $\pm 15^{\circ}$ dip latitude with some wavelike structure. A large geomagnetic storm which began on October 31 is probably responsible for altering the phase of the quiet time vertical $\mathbf{E} \times$ B drift velocity, since the observations can be accounted for by a drift model which exhibits strong downward drift after 1800 LT as opposed to the quiet time model in which downward drift commences 3 hours later at 2100 LT. The normal feature of peaks in the 1304 - and $1356-\AA$ emission at $\pm 15^{\circ}$ dip latitude with a deep trough in between implies that the postsunset upward $\mathbf{E} \times \mathbf{B}$ drift observed as a common occurrence by Woodman [1970] at Jicamarca, Peru, is also a common feature in both the Asian and the Pacific sectors. Also, threefold decreases in the 1304 - and $1356-\AA$ emission rates on November 4 in the Asian sector between $63^{\circ} \mathrm{E}$ and $143^{\circ} \mathrm{E}$ indicate that either (1) the neutral atmospheric composition was altered by the geomagnetic disturbance with a threefold increase in the $\mathrm{N}_{2}$ density at low latitudes or (2) downward drift was exceptionally strong and lowered the $F$ layer well below its quiet time altitude and into a higher loss rate region.

Finally, the fact that $1304-\AA$ emission is optically thick while $1356-\AA$ emission is optically thin allows one to estimate the height of the $F$ layer relative to the satellite by measuring the $1304 / 1356-\hat{A}$ ratio. It is demonstrated that a ratio of 6 maps $H_{\max }\left(F_{2}\right)$ extremely well, independent of the adopted $\mathrm{E} \times \mathrm{B}$ drift model, and that the $R=3$ level lies roughly $70 \mathrm{~km}$ above $H_{\max }\left(F_{2}\right)$ while the $R=9$ level lies $25 \mathrm{~km}$ below.

Acknowledgments. We thank C. A. Barth for making the Ogo 4 data available. We also thank $R$. Meier for providing us with some NRL Ogo 4 data and D. E. Anderson for making his radiative transfer calculations available before publication. We are grateful to $S$. Schaffner for her help in the data reduction and to $R$. Osman-Jouchoux for editing the manuscript. This work was supported by the National Aeronautics and Space Administration under grants NGR-06-003-127 and NGL-06-003-052. The National Center for Atmospheric Research is sponsored by the National Science Foundation.

The Editor thanks J. A. Bittencourt and R. R. Meier for their assistance in evaluating this paper.

\section{REFERENCES}

Anderson, D. E., R. R. Meier, and C. S. Weller, Observations of far and extreme ultraviolet $\mathrm{O} I$ emissions in the tropical ionosphere, Planet Space Sct., 24, 945, 1976.

Anderson, D. N., Theoretical calculations of the $F$ region tropical ultraviolet airglow intensity, J. Geophys. Res., 77, 4782, 1972.

Anderson, D. N., A theoretical study of the ionospheric $F$ region equatorial anomaly, 1, Theory, Planet. Space Sci., 2I, 409, $1973 a$.

Anderson, D. N., A theoretical study of the ionospheric $F$ region equatorial anomaly, 2, Results in the American and Asian sectors, Planet. Space Sci., 2I, 421, 1973 b.

Anderson, D. N., and R. G. Roble, The effect of vertical $\mathbf{E} \times \mathbf{B}$ ionospheric drifts on $F$ region neutral winds in the low-latitude thermosphere, J. Geophys. Res., 79, 5231, 1974.

Barth, C. A., and E. F. Mackey, Ogo-4 ultraviolet airglow spectrometer, IEEE Trans. Geosci. Elec., 7, 114, 1969.
Barth, C. A., and S. Schaffner, Ogo 4 spectrometer measurements of the tropical ultraviolet airglow, J. Geophys. Res., 75, 4299, 1970.

Baxter, R. G., and P. C. Kendall, A theoretical technique for evaluating the time independent effects of general electrodynamic drifts in the F2-layer of the ionosphere, Proc. Roy. Soc., Ser. A, 304, 171, 1968.

Bedinger, J. F., Measurement of winds above 200 kilometers, J. Geophys. Res., 75, 683, 1970.

Bittencourt, J. A., and B. A. Tinsley, Tropical $F$ region winds from $O \mathrm{I}$ 1356- $\hat{A}$ and $[\mathrm{O} \mathrm{I}]$ 6300-A emissions, 1, Theory, J. Geophys. Res., 81, 3781,1976

Bittencourt, J. A., B. A. Tinsley, G. T. Hicks, and E. J. Reed, Tropical $F$ region winds from $O$ I $1356-\hat{A}$ and $O$ I $6300-\hat{A}$ emissions, 2 , Analysis of Ogo 4 data, J. Geophys. Res., 81, 3786, 1976.

Carruthers, G. R., and T. Page, A pollo 16 far ultraviolet spectra of the terrestrial airglow, J. Geophys. Res., 81, 1683, 1976.

Challinor, R. A., Neutral air winds in the ionospheric $F$-region for an asymmetric global pressure system, Planet. Space Sci., 17, 1094, 1969.

Chandra, S., E. 1. Reed, R. R. Meier, C. B. Opal, and G. T. Hicks, Remote sensing of the ionospheric $F$ layer by use of $O$ I $6300-\hat{A}$ and O I 1356-Á observations, J. Geophys. Res., 80, 2327, 1975.

Gérard, J.-C., and C. A. Barth, Ogo 4 observations of the ultraviolet auroral spectrum, Planet. Space Sci., 24, 1059-1063, 1976.

Gérard, J.-C., and C. A. Barth, High-latitude nitric oxide in the lower thermosphere, J. Geophys. Res., 82, 674-680, 1977.

Hanson, W. B., Radiative recombination of atomic oxygen ions in the nighttime $F$ region, J. Geophys. Res., 74, 3720, 1969.

Hanson, W. B., A comparison of the oxygen ion-ion neutralization and radiative recombination mechanisms for producing the ultraviolet nightglow, J. Geophys. Res., 75, 4343, 1970.

Harper, R. M., Observation of a large nighttime gravity wave at Arecibo, J. Geophys. Res., 77, 1311, 1972.

Hicks, G. T., and T. A. Chubb, Equatorial aurora/airglow in the far ultraviolet, J. Geophys. Res., 75, 6233, 1970.

Jacchia, L. G., New static models of the thermosphere and exosphere with empirical temperature profiles, Rep. 313, p. 50, Smithson. Astrophys. Observ., Cambridge, Mass., 1970.

Julienne, P. S., J. Davis, and E. Oran, Oxygen recombination in the tropical nightglow, J. Geophys. Res., 79, 2540, 1974.

Kendall, P. C., and W. M. Pickering, Magnetoplasma diffusion at $F 2$ region altitudes, Planet. Space Sci., 15, 825, 1967.

Knudsen, W. C., Tropical ultraviolet nightglow from oxygen ion-ion neutralization, J. Geophys. Res., 75, 3862, 1970.

Kulkarni, P. V., Tropical airglow, Ann. Geophys., 30, 105, 1974

Meier, R. R., and P. Mange, Spatial and temporal variations of the Lyman alpha airglow and related hydrogen distributions, Planet. Space Sci., 21, 309, 1973.

Meier, R. R., and C. B. Opal, Tropical ultraviolet arcs: Comparison of brightness with $f_{0} F_{2}, J$. Geophys. Res., 78, 3189, 1973.

Meier, R. R., and D. K. Prinz, Observations of the O I 1304-Â airglow from Ogo 4, J. Geophys. Res., 76, 4608, 1971.

Porter, H. S., S. M. Silverman, and T. F. Tuan, On the behavior of airglow under the influence of gravity waves, J. Geophys. Res., 79. $3827,1974$.

Prölss, G. W., and U. von Zahn, Esro 4 gas analyzer results, 2, Direct measurements of changes in the neutral composition during an ionospheric storm, J. Geophys. Res., 79, 2535, 1974.

Rishbeth, H., Polarization fields produced by winds in the equatorial F region, Planet. Space Sci., 19, 357, 1971.

Roble, R. G., B. A. Emery, J. E. Salah, and P. B. Hays, Diurnal variation of neutral thermospheric winds determined from incoherent scatter radar data, J. Geophys. Res., 79, 2868, 1974.

Sheffer, E. K., Nocturnal emission of the atmosphere in the $1304 \AA$ oxygen line at low geomagnetic latitudes (in Russian), Kosm. Issled., 9, 74, 1971.

Sterling, D. L., W. B. Hanson, R. J. Moffett, and R. G. Baxter, Influence of electromagnetic drifts and neutral air winds on some features of the $F_{2}$ region, Radio Sci., 4, 1005, 1969.

Strickland, D. J., and D. E. Anderson, The O I 1304- $\AA$ nadir intensity/column production rate ratio and its application to airglow studies, J. Geophys. Res., 82, this issue, 1977.

Thomas, G., Observations of atomic hydrogen and oxygen from the Ogo satellite, Space Res., 10, 572, 1970.

Thomas, G., and D. E. Anderson, Global atomic hydrogen density derived from Ogo-6 Lyman alpha measurements, Planet. Space Sci., 24, 303, 1976.

Thomas, R. J., and T. M. Donahue, A nalysis of Ogo 6 observations of 
the O I 5577-Å tropical nightglow, J. Geophys. Res., 77, 3557, 1972.

Thuillier, G., and J. E. Blamont, Vertical red line $6300 \AA$ distribution and tropical nightglow morphology in quiet conditions, in Physics and Chemistry of Upper Atmospheres, edited by B. M. McCormac, p. 219, D. Reidel, Dordrecht, Netherlands, 1973.

Tinsley, B. A., and J. A. Bittencourt, Determination of $F$ region height and peak electron density at night using airglow emissions from atomic oxygen, J. Geophys. Res., 80, 2333, 1975.

Tinsley, B. A., A. B. Christensen, J. A. Bittencourt, H. Gouveia, P. D. Angreji, and $H$. Takahashi, Excitation of oxygen permitted line emissions in the tropical nightglow, J. Geophys. Res., 78, 1174, 1973.

Trinks, H., K. H. Fricke, U. Laux, G. W. Prölss, and U. von Zahn, Esro 4 gas analyzer results, 3, Spatial and temporal structure of the mid-latitude atmosphere during a geomagnetic storm, J. Geophys. Res., 80, 4571, 1975.

Woodman, R. F., Vertical drift velocities and east-west electric fields at the magnetic equator, J. Geophys. Res., 75, 6249,-1970.

Woodman, R. F., East-west ionospheric drifts at the magnetic equator, Space Res., 12, 191, 1972.

World Data Center A, Data on solar-geophysical activity, October 24November 6, 1968, Rep. UAG 8, Dep. of Commer., Boulder, Colo., 1970.

(Received July 16, 1976; accepted December 2, 1976.) 